\title{
Mortality due to air pollution: how to interpret the results
}

\author{
Ari Rabl \\ Ecole des Mines, 60 boul. St.-Michel, Paris
}

\begin{abstract}
This paper explains why the number of deaths is not appropriate for causes of death that are merely a contributing rather than identifiable; only LLE (loss of life expectancy) is a meaningful indicator for the total impact of air pollution. Short term (time series) studies provide only information on a change in the number of deaths per day, without any information on the corresponding LLE, by contrast to long term (cohort) studies which yield a change in age specific mortality from which LLE can be calculated using life table data. If one multiplies the number of deaths found by short term studies by an assumed loss per death, one finds that the implied LLE only a very small fraction of the loss implied by long term studies. Results are shown for the LLE from exposure to a pulse of $\mathrm{PM}_{2.5}$, as implied by the long term study of adults published by Pope et al [1995], as well as for infant mortality, based on Bobak and Leon [1999]; the latter turns out to be about ten percent of the LLE among adults. Taking a $50 \%$ to $70 \%$ reduction of $\mathrm{PM}_{2.5}$ as a reasonable policy goal, the results imply a corresponding increase of LLE in urban areas of EU and USA by roughly half a year.
\end{abstract}

\section{Introduction}

In recent years, many studies have attempted to quantify the impacts of mortality due to air pollution [ORNL/RFF 1994, Rowe et al. 1995, ExternE 1998, Kuenzli et al 2000 and others]. Whereas all studies before 1996 calculated a number of premature deaths, there has been a growing recognition in recent years that it is more meaningful to look at loss of life expectancy (LLE). In particular, it is not reasonable to attribute the same benefit to the avoidance of an air pollution death, with an LLE in the order of months, as to an accident which claims on average 30 to 40 years. Therefore the ExternE [1998] Project has based the monetary valuation of air pollution mortality 
on LLE, and economists have begun to evaluate the willingness-to-pay to increase life expectancy [Johannesson \& Johansson 1996, Krupnick et al 2000] (by contrast to previous "value of life" studies that are based on accidental deaths).

It has also been recognized that the full impact of air pollution on health is much larger than what can be measured by the easy and widely used time series epidemiology (which identifies only acute impacts, i.e. impacts that are observable within a few days after exposure to air pollution). Unfortunately it is very difficult and costly to measure the total impacts (short plus long-term), and there are only few long-term studies available. However, in recent years three important epidemiological studies, of the prospective cohort type, have examined the long-term impacts. Two of these [Dockery et al. 1993, Pope et al. 1995] have found positive correlations between exposure to particles and long term mortality (also called chronic mortality in contrast to the acute, or short term, mortality measured by time series studies), while the third [Abbey et al. 1999] found a significant positive correlation with long term mortality for men but not for women.

However, there continues to be confusion about the interpretation of epidemiological studies of air pollution mortality and the use of impact indicators for environmental policy decisions. In particular some authors misinterpret the studies of long term mortality by estimating a number of premature deaths. As an explanation I show that, by contrast to primary causes of death (such as accidents or cancers), the total number of premature deaths due to contributing causes (such as air pollution, unhealthy food or lack of exercise) is much higher than what can be observed by epidemiological studies because it is obscured by an unknown amount of "mortality displacement". Furthermore, number of deaths for contributing causes cannot be added, whereas LLE can. Therefore number of deaths is not meaningful for risk factors that shorten life but are not observable as the cause of an individual death; rather the appropriate impact indicator is LLE.

By means of a model that is simple yet contains the essential features, I examine what kind of impact indicators can be extracted from epidemiological studies of air pollution mortality. I show that epidemiological studies of the time series type measure a change in the number of deaths per day without any information on the LLE per death; only acute effects (i.e. due to short term exposure) are taken into account. Long term epidemiological studies can measure the total impact of air pollution or other contributing causes on mortality; their results are expressed as in increase in age-specific mortality from which LLE can be calculated.

Finally I present numerical results for the LLE implied by air pollution, and I put the numbers in perspective by showing how much the life expectancy could be increased by reducing the ambient concentration of particulate matter.

\section{Observability}

Let us take a stationary population (birthrate $=$ death rate $=$ constant) whose daily death count is $\mathrm{n}_{0}$ in the absence of pollution. Consider the effect of an exposure pulse at $t=0$, for a series of models, illustrated in Fig.1, that become progressively more realistic. In the simplest model, Fig.1a, all individuals who are affected die 
between $\tau$ (delay time) and $\tau+\Delta t$ after the pulse, and their life span is shortened by $\Delta \mathrm{L} . \Delta \mathrm{t}$ is the period over which the data are aggregated, i.e. 1 day for daily death counts. The increase $\Delta \mathrm{n}$ in daily death count is followed by an equal decrease after $\Delta \mathrm{L}$. This phenomenon, sometimes called "mortality displacement", is a simple consequence of the fact that everybody dies exactly once. With the generalization in Fig. $1 \mathrm{~b}$ all individuals who are affected die over a range of delay times $\left\{\tau_{i}\right\}$ after the pulse and lose $\Delta \mathrm{L}$. In Fig. $1 \mathrm{c}$ I suppose that all individuals who are affected die between $\tau$ and $\tau+\Delta t$ after the pulse and suffer a range of losses $\left\{\Delta \mathrm{L}_{\mathrm{i}}\right\}$.

Finally, in parts d) and e) of Fig.1, there is both a range of delay times $\left\{\tau_{i}\right\}$ and a range of losses $\left\{\Delta \mathrm{L}_{\mathrm{i}}\right\}$. Since $\tau_{\mathrm{i}}$ and $\Delta \mathrm{L}_{\mathrm{i}}$ are likely to be long compared to a day, $\mathrm{I}$ show smooth curves instead of the steps in parts a)-c). In part d) the depletion is distinct $\left(\operatorname{Min}\left[\Delta \mathrm{L}_{\mathrm{i}, \mathrm{j}}\right]>\operatorname{Max}\left[\tau_{\mathrm{i}}\right]-\operatorname{Min}\left[\tau_{\mathrm{i}}\right]\right)$ and the total number of deaths is observable: it is the integral under the peak. In part d) the depletion overlaps and the observed death count, indicated by the heavy line, is less than the total number of deaths attributable to the pulse. To reconstruct the true mortality peak from the observed data, one would need precise information on the distributions of $\left\{\tau_{\mathrm{i}}\right\}$ and $\left\{\Delta \mathrm{L}_{\mathrm{i}}\right\}$. But the individual $\Delta \mathrm{L}_{\mathrm{i}}$ are unknowable. Therefore the total number of deaths due to the pulse is not observable for the case with overlap. In principle, if one had data of unlimited accuracy, one could at least distinguish whether there is overlap. But for air pollution the data will never be sufficiently accurate, and in any case it seems most likely that delay times and losses overlap.

\section{Short term studies}

Most dose-response (D-R) functions for health impacts of air pollution are of the acute type, i.e. they have been determined by analyzing time series data and looking for short term correlations between fluctuations of ambient concentration $c$ and incidents of the health end point under consideration; in practice the largest delay $\tau$ between concentration and health end point that is taken into account is five days (although a recent study, using frequency domain log-linear regression, has in effect extended the window of the analysis up to 60 days, and the results suggest that the average loss of life per death is much more than a few days [Samet et al 2000]). The time series approach has the great advantage of being easy to implement and insensitive to the confounders, such as smoking, that plague the determination of chronic D-R functions. The latter requires long term studies. By analogy the terms acute and chronic are also applied to mortality even though the attributes appear strange in that context. 
Transactions on Biomedicine and Health vol 5, (c) 2001 WIT Press, www.witpress.com, ISSN 1743-3525

56 Environmental Health Risk

a)

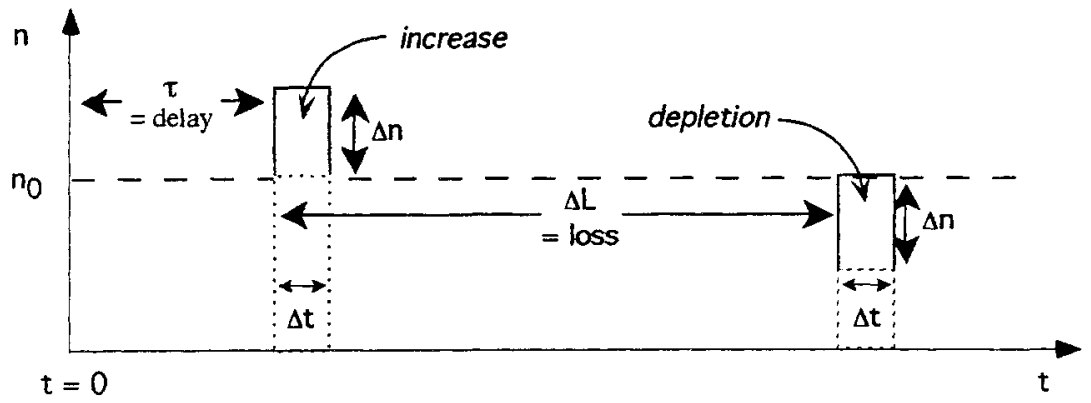

b)

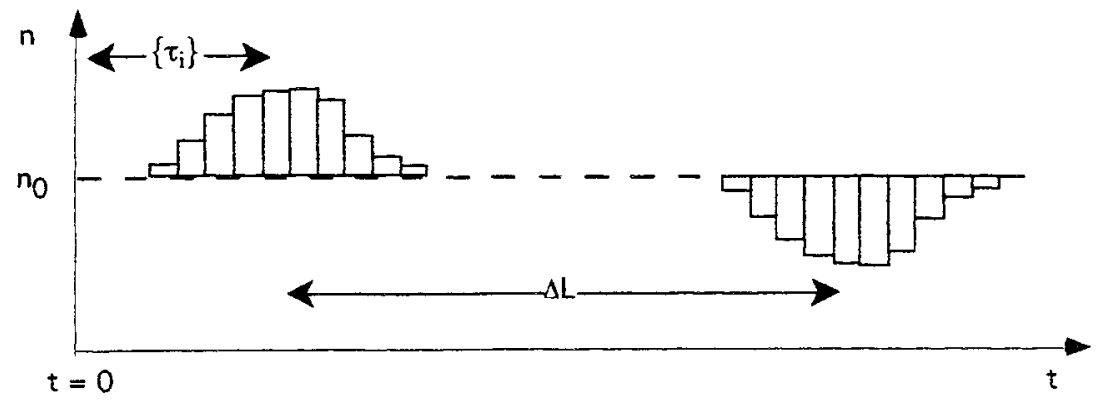

c)

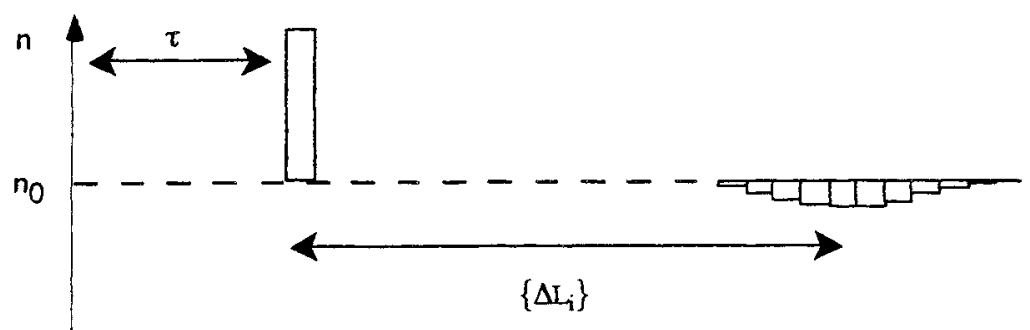

d)

$$
t=0
$$

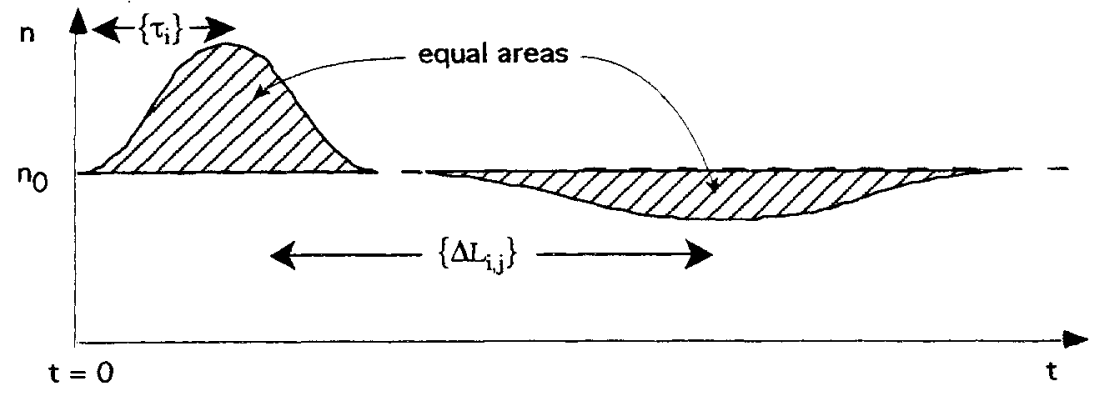


e)

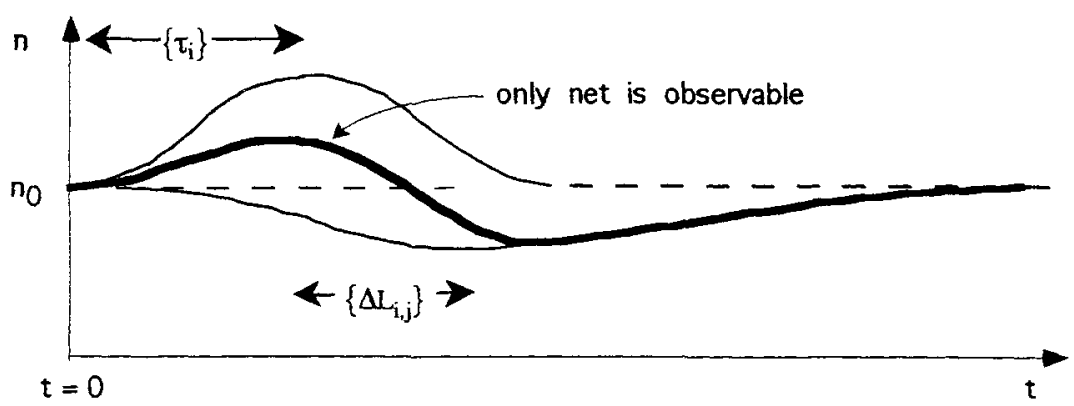

Fig.1. Models for effect of air pollution pulse at $t=0$ on daily death count $n$

a) all affected individuals die between $\tau$ and $\tau+\Delta t$ after the pulse, and their life span is shortened by $\Delta \mathrm{L}$.

b) all affected individuals die over a range of delay times $\left\{\tau_{i}\right\}$ and lose $\Delta L$.

c) all affected individuals die between $\tau$ and $\tau+\Delta t$ and suffer a range of losses $\left\{\Delta \mathrm{L}_{4}\right\}$

d) affected individuals die over a range $\left\{\tau_{i}\right\}$ and suffer a range of losses $\left\{\Delta L_{i}\right\}$ : depletion is distinct.

e) affected individuals die over a range $\left\{\tau_{i}\right\}$ and suffer a range of losses $\left\{\Delta L_{i}\right\}$ : depletion overlaps (the case of air pollution).

D-R functions for acute mortality are obtained from correlations between ambient concentration $c$ and daily death count $n$. If one examines the formal relation between fluctuations of concentration and of death counts, one finds that the resulting $\mathrm{D}-\mathrm{R}$ function is independent of $\Delta \mathrm{L}$. This is easy to see for the model of Fig.1a where a short pollution pulse of concentration increase $\Delta c$ causes $\Delta n$ individuals to die exactly $\Delta \mathrm{L}$ sooner than in the absence of the pulse. In the situation of Fig.la a time series analysis finds that $\Delta \mathrm{n}$ is proportional to $\Delta \mathrm{c}$, independent of $\Delta \mathrm{L}$. This feature does not change for more realistic models with a range of $\Delta \mathrm{L}$. Therefore the usual short term mortality studies observe changes in the daily death count, without providing any information on the loss of life expectancy $\Delta \mathrm{L}$ per death.

\section{Long term studies}

In the long term studies cited above, cohorts in regions with different pollution levels were selected and observed over many years. A key element for the analysis is the age-specific mortality $\mu(x)$, defined such that someone who has reached age $\mathrm{x}$ has a probability $\mu(\mathrm{x}) \Delta \mathrm{x}$ of dying between $\mathrm{x}$ and $\mathrm{x}+\Delta \mathrm{x}$ (usually one chooses $\Delta x=1$ year). The survival data are fitted by the Cox proportionalhazards regression model, assuming that the mortality for a cohort with pollution $c$ is related to the one without pollution by

$\mu(t)=\mu_{0}(t) \exp (\theta c+K)$,

with the parameter $\theta$ to be determined. The term $\mathrm{K}$ serves to account for nonpollution risk factors such as smoking. The factor $\exp (\theta \mathrm{c})$ is reported as 
mortality risk ratio $\mathrm{R}$, or relative risk, for air pollution. The largest relative mortality risk reported by Pope et al is

$\mathrm{R}=\exp (\theta \Delta c)=1.17 \quad$ for $\Delta \mathrm{c}=24.5 \mu \mathrm{g} / \mathrm{m}^{3}$ of $\mathrm{PM}_{2.5}$.

Let $\phi(x)=$ age distribution, defined such that $\phi(x) \Delta x$ is the fraction of the population between ages $x$ and $x+\Delta x$. In a population of $N_{\text {pop }}$ individuals, with age distribution $\phi(x)$ and age-specific mortality $\mu(x)$, the number of deaths per time interval $\Delta t$ (the interval used for specifying $\mu$ ) is

$\mathrm{n}_{\text {deaths }}=\mathrm{N}_{\text {pop }} \int_{0}^{\infty} \phi(\mathrm{x}) \mu(\mathrm{x}) \mathrm{dx}$

If pollution increases $\mu(x)$ by $\Delta \mu(x)$, it is therefore tempting to interpret the quantity

$\Delta n_{\text {deaths }}=N_{\text {pop }} \int_{0}^{\infty} \phi(x) \Delta \mu(x) d x$

as deaths due to this pollution, and several authors have done so. However, that amounts to counting only the area under the heavy line in Fig. le, whereas the true number of deaths due to pollution corresponds to the peak under the thin line; it is larger and unobservable. Eq.4 would be correct for identifiable causes of death such as accidents because they correspond to Fig. Id without overlap.

That something is wrong with the calculation of $\Delta n_{\text {deaths }}$ according to Eq. 4 is also suggested by the following argument. The extra number of deaths of Eq.4 is proportional to the pollution increment, and so is the LLE [Leksell \& Rabl 2001]. This would imply that the LLE per air pollution death (the number turns out to be about 10 years) is independent of the pollution exposure, a result that would be reasonable for cancers but not for cardio-pulmonary deaths associated with PM. In fact, for chronic air pollution mortality the mechanism proposed by Evans and Wolf [1996] is far more plausible: fine particles reduce lung function, in proportion to exposure. Lung function decreases naturally with age, and people die if lung function falls below a critical threshold. With such a mechanism the LLE per death is proportional to exposure.

\section{Loss of life expectancy per $\mu \mathrm{g} / \mathrm{m}^{3}$ of $\mathrm{PM}_{2.5}$}

Since the results of Pope et al are stated as an increase in age-specific mortality, a fairly elaborate calculation, involving life table data, is required to find the life span reduction. A relatively simple steady state analysis has been published by Brunekreef [1997] and by Rabl [1998], recently confirmed by a more detailed analysis to take into account variable pollution exposures [Leksell \& Rabl 2001]. In particular, for a pollution pulse of $1 \mu \mathrm{g} / \mathrm{m}^{3} \mathrm{PM}_{2.5}$ (particulate matter $<2.5 \mu \mathrm{m}$ diameter) lasting 1 year, Leksell \& Rabl find a loss of approximately 
implied by the D-R function of Pope et al [1995]. Variations due to differences in life table data between the USA and the EU change this number only by a few percent.

It is interesting to compare these numbers with the LLE from short term studies. Even though the latter do not provide any information about LLE per death, one can get a rough idea by assuming, for the sake of argument, 6 months per death as population average. Short term studies typically find that the population mortality rate increases by roughly $0.1 \%$ per $\mu \mathrm{g} / \mathrm{m}^{3}$. Taking 10000 deaths $/ \mathrm{yr}$ per million as typical value of the latter, this implies an average LLE of

10000 deaths/yr per million $* 0.001$ per $\mu \mathrm{g} / \mathrm{m}^{3} * 0.5 \mathrm{YOLL} /$ death $=5$ YOLL per million per $\mu \mathrm{g} / \mathrm{m}^{3}$ of $\mathrm{PM}_{2.5}$ per $\mathrm{yr}$

This is less then $1 \%$ of the total found by long term studies. With any reasonable assumption for the LLE per acute death one finds that the mortality observed by short term studies is at most a small contribution to the total impact (and in any case it is included in the results of the long term studies by their very design). This is entirely plausible when one considers what time series studies would be able to observe about mortality from smoking if applied in a hypothetical country where cigarette sales are forbidden on Sundays.

\section{Infant mortality}

Bobak \& Leon [1999] carried out a case-control study of infant mortality in the Czech Republic from 1889 to 1991 . Among the correlations shown in their paper, the most relevant for the present purpose is the relative risk $\mathrm{R}$ for respiratory mortality due to TSP (total suspended particles) during the first 12 months of life, adjusted for all covariates (their Table 3 ); it is

$\mathrm{R}=1.77(95 \% \mathrm{Cl} 1.04-3.01)$ for $50 \mu \mathrm{g} / \mathrm{m}^{3}$ of TSP.

The authors note that "... the associations with mortality were approximately linear". Applying the dose-response relation of Bobak \& Leon to other countries involves uncertainties, because of different levels of air pollution and infant mortality. However, the concentrations during this study were only about a factor of two higher than those found in urban environments of EU and USA, not a large difference in view of the approximate linearity observed by Bobak \& Leon. The infant mortality rates are not very different: 9.6 per 1000 in the Czech Republic and 7.2 per 1000 in the USA. The rate for respiratory infant mortality in the USA is 1.24 per 1000 [Table 30 of NCHS 1999].

For the purpose of comparisons it is instructive to present the mortality impacts in terms of YOLL per $\mu \mathrm{g} / \mathrm{m}^{3}$ for a pollution pulse that lasts one year. Assuming a linear relation between relative risk and concentration $\mathrm{c}$ with a constant of proportionality k, Eq.7 implies 
$\mathrm{R}=1+\mathrm{kc}$

with $\mathrm{k}=0.0154$ per $\mu \mathrm{g} / \mathrm{m}^{3}$ of TSP;

$\mathrm{k}$ is the fraction by which the respiratory infant mortality increases per $\mu \mathrm{g} / \mathrm{m}^{3}$.To estimate the YOLL, a hypothesis is required for the number of years a baby would have lived in the absence of air pollution. Since many babies end up living a normal healthy life despite a fragile infancy, I assume that the loss per infant death is the average life expectancy, about 76 years. Thus 1 obtain

$$
\begin{gathered}
0.00124 \text { deaths } / \text { birth } * 76 \mathrm{YOLL} / \text { death } * 0.0154 \text { per } \mu \mathrm{g} / \mathrm{m}^{3} \\
=0.00145 \mathrm{YOLL} / \text { birth per } \mu \mathrm{g} / \mathrm{m}^{3} \text { of TSP }
\end{gathered}
$$

In 1 year there are 14200 births per year per million in the USA, 11000 in the EU. Hence for a population of one million the loss in the USA is

$$
\begin{gathered}
0.00145 \text { YOLL birth per }\left(\mu \mathrm{g} / \mathrm{m}^{3}\right) * 14.2 \text { births } / \mathrm{yr} \text { per million } \\
=21 \text { Y OLL yr per } \mu \mathrm{g} / \mathrm{m}^{3} \text { of TSP per million }
\end{gathered}
$$

For comparison with Pope et al [1995] one needs to estimate the ratio of $\mathrm{PM}_{2.5} / \mathrm{TSP}$ in the Czech Republic during the study period. Unfortunately no data were available for $\mathrm{PM}_{2.5}$, considered to be the component of TSP that causes most or all of the harm. Since the $\mathrm{PM}_{2.5}$ TSP ratio depends on the pollution sources in the region there is some uncertainty. Based on data in countries where $\mathrm{PM}_{2.5}$ and TSP have been measured, I assume

$\mathrm{PM}_{2.5} / \mathrm{TSP}=0.33$ (range 0.2 to 0.5 )

Dividing Eq. 10 by $\mathrm{PM}_{2.5}$ TSP I find that the implied infant mortality YOLL per $\mathrm{PM}_{2.5}$ is

$$
0.063(0.042 \text { to } 0.105) \text { YOLL/ yr per } \mu \mathrm{g} / \mathrm{m}^{3} \mathrm{PM}_{2.5} \text { per million }
$$

(the parenthesis accounts for the uncertainty about $\mathrm{PM}_{2.5} / \mathrm{TSP}$ and the confidence interval of Eq.7). Hence loss of life expectancy due to infant mortality is only about $10 \%$ ( 6 to $15 \%$ ) of the loss among the adult population. Even though there are large uncertainties in the epidemiological studies, further compounded for the comparison by uncertainties of the $\mathrm{PM}_{2.5} / \mathrm{TSP}$ ratio, it seems unlikely that infant mortality would increase the estimate of population. To explain the small contribution of infant mortality, despite the maximal assumption of 76 years of life lost per infant death, we note that the age-specific mortality around 50 is comparable to the rate for infants and increases rapidly with age; for infant mortality only a one-year cohort is affected by the 1-yr pulse, whereas the results for adults covers all cohorts above 30 .

\section{Implications}

I have shown that short term studies yield correlations between number of deaths per day and pollution, without any information about the LLE per death, by contrast to long term studies that allow calculation of population average LLE but provide no information on the number of deaths attributable to pollution. Short term studies capture only a very small fraction of the total mortality impact. For 
contributing risk factors such as air pollution that cannot be identified as cause of an individual death, only LLE is a meaningful indicator of the total impact on a population.

Combining the LLE for infant mortality with the one for adults, I obtain a total of 660 YOLL per million per $\mu \mathrm{g} / \mathrm{m}^{3}$ of $\mathrm{PM}_{2.5}$ per yr ,

with a one-standard deviation confidence interval from 500 from 900 , estimated from Rabl \& Spadaro [1999].

To put the numbers on LLE from air pollution in perspective, note that typical concentrations of $\mathrm{PM}_{2.5}$ in urban areas of the USA and the EU are around 15 to 20 $\mu \mathrm{g} / \mathrm{m}^{3}$. A reduction by $10 \mu \mathrm{g} / \mathrm{m}^{3}$ is a reasonable policy goal. Multiplying Eq. 13 by $10 \mu \mathrm{g} / \mathrm{m}^{3} * 76 \mathrm{yr}$ for the corresponding difference in life time exposure, one finds,

660 YOLL per million per $\mu \mathrm{g} / \mathrm{m}^{3}$ of $\mathrm{PM}_{2.5}$ per $\mathrm{yr} * 10 \mu \mathrm{g} / \mathrm{m}^{3} * 76 \mathrm{yr}$ $=0.5 \mathrm{YOLL}$ per person for $10 \mu \mathrm{g} / \mathrm{m}^{3}$ of $\mathrm{PM}_{2.5}$ over lifetime.

The reduction by $10 \mu \mathrm{g} / \mathrm{m}^{3}$ increases life expectancy by half a year.

\section{Acknowledgments}

This work has been supported in part by the ExternE Project of the European Commission DG Research. I am grateful to Vladimir Demin, Ingemar Leksell and Richard Wilson for helpful discussions.

\section{References}

Abbey DE, N Nishino, WF McDonnell, RJ Burchette, SF Knutsen, WL Beeson \& JX Yang 1999. "Long-term inhalable particles and other air pollutants related to mortality in nonsmokers". Am. J. Respir. Crit. Care Med., vol. $159,373-382$.

Bobak M \& DA Leon 1999. "The effect of air pollution on infant mortality appears specific for respiratory causes in the postneonatal period". Epidemiology 10(6), 666-670.

Brunekreef B 1997. "Air pollution and life expectancy: is there a relation?" Occupational and Environmental Medicine, vol.54, pp.781-784.

Dockery DW, CA Pope III, Xiping Xu, JD Spengler, JH Ware, ME Fay, BG Ferris \& FE Speizer 1993. "An association between air pollution and mortality in six US cities". New England J of Medicine, vol.329, p.17531759 (Dec. 1993).

Evans J \& S Wolff 1996. "Modeling of air pollution impacts: one possible explanation of the observed chronic mortality". Chapter 9, pp189-204 of Wilson R \& JD Spengler, editors 1996. Particles in Our Air: Concentrations and Health Effects. Harvard University Press, Cambridge, MA. 
ExternE 1998. ExternE: Externalities of Energy. Vol.7: Methodology 1998 Update (EUR 19083); Vol.8: Global Warming (EUR 18836); Vol.9: Fuel Cycles for Emerging and End-Use Technologies, Transport and Waste (EUR 18887); Vol.10: National Implementation (EUR 18528). Published by European Commission, Directorate-General XII, Science Research and Development. Office for Official Publications of the European Communities, L-2920 Luxembourg. Results are also available at http://ExternE.jrc.es/publica.html.

Johannesson M \& P-O Johansson 1996. "To be or not to be, that is the question: an empirical study of the WTP for an increased life expectancy at an advanced age". $J$ Risk and Uncertainty, 13, 163-174.

Krupnick A, A. Alberini, M. Cropper, N. Simon, B. O'Brien, R. Goeree \& M. Heintzelman 2000. "What are Older People Willing to Pay to Reduce Their Risk of Dying?" Resources for the Future, 1616 P Street, NW, Washington, DC 20036. Paper presented to the AERE Sessions, ASSA Meetings, Boston, Mass., January 7, 2000.

Kuenzli N, R Kaiser, S Medina, M Studnicka, O Chanel, M Herry, F Horak, V Puybonnieux-Texier, $P$ Quénel, J Schneider, R Seetaler, J-C Vergnaud \& H Sommer 2000. "Public health impact of outdoor and traffic-related air pollution: a European assessment". Lancet, 356 (Sept.), 795-801.

Leksell L \& A Rabl 2001. "Air Pollution and Mortality: Quantification and Valuation of Years of Life Lost". Risk Analysis, in press.

NCHS 1999. National Center for Health Statistics, Hyattsville, Maryland. National Vital Statistics Reports, Vol. 47, No. 19, June 30, 1999. Available at http://www.cdc.gov/nchs/fastats/infmort.htm.

ORNL/RFF 1994. External Costs and Benefits of Fuel Cycles. Prepared by Oak Ridge National Laboratory and Resources for the Future. Edited by Russell Lee, Oak Ridge National Laboratory, Oak Ridge, TN 37831.

Pope CA, MJ Thun, MM Namboodri, DW Dockery, JS Evans, FE Speizer \& CW Heath 1995. "Particulate air pollution as a predictor of mortality in a prospective study of US adults". Amer. J. of Resp. Critical Care Med., vol.151, 669-674.

Rabl A 1998. "Mortality risks of air pollution: the role of exposure-response functions". Journal of Hazardous Materials, vol.61, pp.91-98.

Rabl A \& JV Spadaro. 1999. "Environmental Damages and Costs: an Analysis of Uncertainties". Environment International, Vol.25, 29-46 (1999)

Rowe RD, CM Lang, LG Chestnut, D Latimer, D Rae, SM Bernow \& DWhite. 1995. The New York Electricity Externality Study. Oceana Publications, Dobbs Ferry, New York.

Samet JM, F Dominici, SL Zeger, J Schwartz \& W Dockery. 2000. "National Morbidity, Mortality, and Air Pollution Study, Part I: Methods and Methodologic Issues". Research report 94, Part 1, The Health Effects Institute, Cambridge MA. 